\title{
Tracking the Calcium Magnesium-Alumino-Silicate (CMAS) Infiltration into an Air-Plasma Spray Thermal Barrier Coating using X-ray Imaging
}

DOI:

10.1016/j.scriptamat.2019.09.016

\section{Document Version}

Accepted author manuscript

Link to publication record in Manchester Research Explorer

Citation for published version (APA):

Zhang, X., Shan, X., Withers, P., Zhao, X., \& Xiao, P. (2020). Tracking the Calcium Magnesium-Alumino-Silicate (CMAS) Infiltration into an Air-Plasma Spray Thermal Barrier Coating using X-ray Imaging. Scripta Materialia, 176, 94-98. https://doi.org/10.1016/j.scriptamat.2019.09.016

\section{Published in:}

Scripta Materialia

\section{Citing this paper}

Please note that where the full-text provided on Manchester Research Explorer is the Author Accepted Manuscript or Proof version this may differ from the final Published version. If citing, it is advised that you check and use the publisher's definitive version.

\section{General rights}

Copyright and moral rights for the publications made accessible in the Research Explorer are retained by the authors and/or other copyright owners and it is a condition of accessing publications that users recognise and abide by the legal requirements associated with these rights.

\section{Takedown policy}

If you believe that this document breaches copyright please refer to the University of Manchester's Takedown Procedures [http://man.ac.uk/04Y6Bo] or contact uml.scholarlycommunications@manchester.ac.uk providing relevant details, so we can investigate your claim.

\section{OPEN ACCESS}


Tracking the Calcium-Magnesium-Alumino-Silicate (CMAS) Infiltration into an Air-Plasma Spray Thermal Barrier Coating using X-ray Imaging

\author{
Xun Zhang ${ }^{\mathrm{a}, \mathrm{c}, 1}{ }^{1}$, Xiao Shan ${ }^{\mathrm{b}}$, Philip J. Withers ${ }^{\mathrm{a}, \mathrm{c}}$, Xiaofeng Zhao ${ }^{\mathrm{b}}$, Ping Xiao ${ }^{\mathrm{a}, \mathrm{c}^{*}}$ \\ aHenry Royce Institute, School of Materials, The University of Manchester, \\ Manchester M13 9PL, UK \\ bShanghai Key Laboratory of Advanced High-Temperature Materials and Precision \\ Forming, Shanghai Jiao Tong University, 200240 P. R. China
}

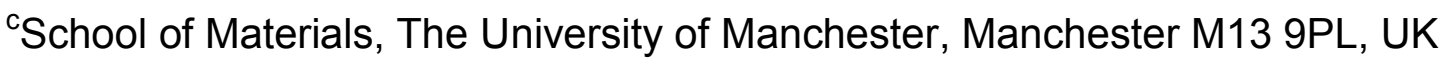

\begin{abstract}
The progressive infiltration of a free-standing air plasma spray (APS) thermal barrier coating (TBC) by Calcium-Magnesium-Alumino-Silicate (CMAS) at $1250^{\circ} \mathrm{C}$ is investigatedfollowed non-destructively by time-lapse $\mathrm{X}$-ray micro-computed tomography $(\mu-C T)$. The top $\sim 50 \mu \mathrm{m}$ of the TBC expands rapidly (within the first 20 $\min$ ) by as much as $70 \%$ due to the physical ingress of the CMAS along the splat boundaries and becomes exfoliated. The romainder of the TBC swolls at a slower rate (ultimately by $15 \%$ ) but remains intact. The ingress and resulting exfoliation are shown to be driven by capillary forces andwith the exfoliated depth dependsdependant on the CMAS loading. The remainder of the TBC swells at a slower rate (ultimately by $15 \%$ ) but remains intact.
\end{abstract}

Key words: aero engine; high temperature; failure; environment; volcano ash

Thermal barrier coatings (TBCs) are widely used in the gas-turbine engines to provide thermal protection for the metallic components [1-4]. The state of the art TBCs consist of a 7-8 wt.\% $\mathrm{Y}_{2} \mathrm{O}_{3}$-stabilized $\mathrm{ZrO}_{2}$ (7YSZ) topcoat, a NiCoCrAlY or $\mathrm{Pt} / \mathrm{Al}$ diffusion bond coat and a Ni-based superalloy substrate $[2,5]$. Although the application of TBCs has allowed an increase in gas temperatures, the demand for even higher operating temperatures is posing materials issues for the current TBCs $[2,4,6,7]$. For example, silicate debris (e.g. sand, volcano ash etc.) ingested by the engine adheres to the surface of TBCs and forms glassy calcium-magnesiumalumino-silicate (CMAS) [8]. At high temperatures $\left(\sim 1230^{\circ} \mathrm{C}\right.$ [9]) the CMAS is molten *Corresponding author: Ping Xiao (p.xiao@manchester.ac.uk). ${ }^{1}$ Current address: Department of Engineering Science, University of Oxford, Parks Road, Oxford, OX1 3PJ, UK 
and can wet the TBC surface. Penetration of CMAS into the pores in the topcoat

X-ray micro computed tomography $(\mu-C T)$ has already been used for TBC characterisation, for example to track microstructure evolution as a function of thermal exposure including TGO growth [18], the localised rumpling of TGO [19], the displacement induced by thermal treatment [20], as well as cracking and changes in porosity within the YSZ topcoat [21, 22]. More recently, the evolution of pores in the TBCs under volcanic ash corrosion has been investigated by X-ray CT [23]. However, the evolution of TBC microstructure during CMAS infiltration has yet to be observed.

Here the infiltration of CMAS into an APS TBC is followed by time-lapse X-ray $\mu-C T$. The aims are (1) to build-up an overarching view of the CMAS infiltration process and (2) to observe the microstructural evolution of the TBC during CMAS infiltration in order to explore the kinetics of CMAS infiltration and the associated volume changes in the TBC to underpin life-time prediction models. 
8 wt. $\% \mathrm{Y}_{2} \mathrm{O}_{3}$-stabilized $\mathrm{ZrO}_{2}$ (8YSZ) was deposited onto a Hastelloy-X plate having a NiCoCrAlY bond coat by APS. The thickness of the coating was about $280 \mu \mathrm{m}$. The plate was cut into $7 \times 5 \mathrm{~mm}^{2}$ rectangles. To obtain free-standing TBCs, the rectangles were immersed in aqua regia to remove the metallic substrate. CMAS paste comprising $33 \mathrm{CaO}-9 \mathrm{MgO}-13 \mathrm{AlO}_{1.5}-45 \mathrm{SiO}_{2}$ mol\% was prepared by mixing the powders of each oxide constituent and attrition milling the blend in isopropanol. The as-prepared paste was applied to the middle of the free-standing TBC followed by a 5 -min treatment at $1250{ }^{\circ} \mathrm{C}\left(10{ }^{\circ} \mathrm{C} / \mathrm{min}\right.$ heating and cooling rate $)$ in order for the CMAS paste to wet the TBC surface.

In order to correlate contrast of features recorded by micro-CT with conventional scanning electron microscopy (SEM) sections, a $500 \mu \mathrm{m}$ diameter cylindrical sample was cut from the CMAS-coated APS TBC plate using a precise laser cutting machine [24]. An X-ray $\mu$-CT scan was acquired prior to destructive sectioning to extract a central section sample for SEM for side by side comparison.

To follow the microstructural evolution at different stages of CMAS infiltration, a matchstick specimen measuring $1 \mathrm{~mm} \times 3 \mathrm{~mm} \times 0.3 \mathrm{~mm}$ was cut from the centre of the CMAS-coated freestanding TBC. A previous study on the same TBC sample has shown that a large deformation can be induced by CMAS infiltration after heat treatment at $1250{ }^{\circ} \mathrm{C}$ for $\sim 98 \mathrm{~min}$ [9]. Once a tomograph of the specimen in the asreceived state had been collected, the specimen was heat treated in air to $1250{ }^{\circ} \mathrm{C}$ for 20 min using a chamber furnace. During the heat treatment, the heating and cooling rate was kept at $5{ }^{\circ} \mathrm{C} / \mathrm{min}$. After cooling to ambient, an X-ray tomograph of the same region of interest was collected before the specimen was put back into the furnace for the next heat treatment step to acquire a time-lapse sequence.

A Zeiss Xradia Versa 520 X-ray microscope (XRM) was used to acquire the X-ray tomographs. For all the CT scans, the X-ray tube was operated at $120 \mathrm{kV}$. Each scan comprises 1601 projections equi-angularly distributed over $360^{\circ}$ sample rotation. The reconstructed virtual slices have a voxel size of $0.72 \mu \mathrm{m}$. 
The X-ray tomographs collected at different stages of thermal exposure were coregistered to a single sample coordinate system. To enable correlative characterisation [25], the datasets were pre-aligned manually and registered using the 'Register Image' module in Avizo 9.4 (Thermo Scientific). The registered datasets were re-sliced to pick out virtual slices showing the same region of interest (Rol) of the sample at different stages of heat treatment.

After co-registration, Digital volume correlation (DVC) was undertaken for the intact layer between successive tomographs using the DaVis 8 (LaVision) software. A multi-pass correlation algorithm was chosen with the window size decreasing from $128 \times 128 \times 128$ voxels to $24 \times 24 \times 24$ voxels over 4 iterations and the window overlap was kept at $50 \%$. After each pass, the displacement vector is deleted if its correlation value is less than 0.9 . Moreover, the missing values on the grid points where the displacement vectors have been deleted are added via bilinear interpolation. The relative volumetric change of the sample can be calculated using the divergence of the displacement field as [26]:

$$
\Theta=\nabla \cdot \overline{\boldsymbol{u}}=\frac{\partial u_{x}}{\partial \mathrm{x}}+\frac{\partial u_{y}}{\partial \mathrm{y}}+\frac{\partial u_{z}}{\partial \mathrm{z}}
$$

Prior to differentiation, a median filter $(3 \times 3$ kernel size $)$ is applied to the displacement field in order to reduce noise.

Figure 1 compares a virtual slice taken from the X-ray tomograph of the freestanding APS TBC after applying the CMAS with an SEM (BSE) micrograph obtained destructively for the same slice (Rol). The CMAS is observed as a dark region (almost as dark as the pores) in the CT image because of the low atomic number of the constituents, whereas it is much lighter in the SEM image. The higher spatial resolution SEM image confirms the spherical features showing the darkest contrast on the $\mu$-CT virtual slices (e.g. yellow arrow) are pores and the grey regions, which tend to be aligned horizontally (e.g. yellow square), correspond to inter-splat gaps filled by partially consolidated YSZ particles. The $\mu-C T$ virtual slice demonstrates that the fragmented YSZ zones evident in the SEM sections have not been introduced post mortem by the grinding and polishing process. Further, crosscorrelation confirms that the crack-shaped features (highlighted by the red ellipse) 
are inter-splat cracks. Very fine cracks (less than $0.6 \mu \mathrm{m}$ wide) cannot be resolved by $\mathrm{X}$-ray $\mu-\mathrm{CT}$.

Figure 2 shows virtual cross-sections taken from the center of the thermally exposed coupon after different thermal exposure times. By following the microstructure evolution in this region of interest (Rol), it is possible to appreciate the kinetics of the CMAS infiltration process. Figure 2 (a) shows that the CMAS has completely covered the top surface of the TBC before infiltration. The CMAS loading on this specimen was estimated from the tomographs to be $22.3 \pm 2.6 \mathrm{mg} / \mathrm{cm}^{2}$ (Appendix A).

The CT image sequence shows that the CMAS infiltration creates two distinct regions within the TBC. After 20mins (Figure 2 (b)), the CMAS has infiltrated the upper 20 50 $\mu \mathrm{m}$ of the TBC (i.e. the region above the red dash line in Figure 2 (b)) which as a result has become exfoliated from the underlying material. Exfoliation has followed the morphology of the splats, as shown by the yellow ellipse in Figure 2 (b). This suggests that the CMAS tends to attack the inter-splat gaps preferentially. Pores have developed in the exfoliated layer (e.g. red circles in Figure 2 (b)) during the first $20 \mathrm{~min}$. The largely defect-free region of the coating near the very top of the coating (e.g. above the yellow dash line) has retained its morphology despite being in direct contact with the CMAS and has rafted upwards lifted by the exfoliation beneath it. In addition, pores are seen under the lifted splats. In some cases, cracks have developed within the lifted YSZ as indicated by the red arrow in Figure 2 (b).

At longer exposure times, the exfoliated surface region appears to 'deflate' somewhat while the CMAS infiltrates deeper into the TBC primarily via the boundaries of the splats. This is accompanied by a slight increase in the depth of the exfoliated layer which takes in more TBC splats (its extent delineated by the red dashed lines in Figure 2 (c) and (d)). Inside the exfoliated layer, which has developed in the first 20 min of heat treatment, a large number of small spherical pores (e.g. yellow circle in Figure 2 (c)) have formed after $40 \mathrm{~min}$. Such pores 
haven't agglomerated into larger pores. The larger spherical pores that have developed in the first 20 min (e.g. red circles in Figure 2 (b)) have deflated somewhat as the CMAS has penetrated deeper into the coating. The surface crack on the lifted YSZ has closed as the large pore beneath it deflates. The contrast for the CMAS in the exfoliated layer has become brighter as heat treatment proceeds. This could be a result of the dissolution of heavy element ions such as $\mathrm{Y}^{3+}$ and $\mathrm{Zr}^{4+}$ into the CMAS since the contrast in the $\mathrm{CT}$ virtual slices reflects the X-ray mass attenuation coefficient of the probed sample. This could have changed the viscosity of the remaining CMAS and led to different behavior of the pores at different stages of heat treatment [12].

It is noteworthy that the underlying intact (unexfoliated) region of the TBC appears to become infused with CMAS at longer exposure times (evident as a darker contrast compared with the $Y S Z$ in the X-ray $\mu$-CT virtual slices). Comparison of Figure 2 (a) and (c) indicates that the CMAS has completely penetrated the free-standing coating as the splats at the bottom of the coating appear to have become separated (e.g. the region indicated by the black dashed line).

The temporal evolution of the average volume expansion is plotted in Figure 3. The volume expansion in the top $50 \mu \mathrm{m}$ of the coating surface is marked and can be estimated directly from the tomograms according to:

$$
\theta=\frac{V_{t}-V_{0}}{V_{0}}
$$

where $V_{0}$ is the initial volume of the exfoliated and $V_{t}$ is the volume of the same region after different treatment steps.

The average volume expansion in the exfoliated layer is estimated to be $70 \%$ after the first $20 \mathrm{~min}$. This essentially matches the sum of the volume of the CMAS plus that of the TBC which became exfoliated. This indicates that the depth of the exfoliated layer could be related to the CMAS loading. The following $20 \mathrm{~min}$ of thermal exposure has led to a small decrease in the volume expansion (to about 
$60 \%$ ). Combining with the microstructure observation in Figure 2, this decrease in volume expansion is largely due to the deflation of the pores and the infusion of the CMAS into the intact layer. Eventually, the volume expansion has stabilised at around $60 \%$.

Regarding the intact layerunderlayer, no appreciable volume expansion occurs in the first 20 min. However, DVC reveals a volume expansion as the CMAS begins to infuse into the intact layer over the next 20 mins and that this continues, if somewhat more slowly, over the following 20 mins, as shown in Figure 3, being greatest nearest the exfoliated layer and decreasing towards the backface (the detailed DVC results are shown in Appendix $\mathrm{C}$ ). The fact that a dilatational strain is recorded through this whole region corroborates the inference from Figure 2 that there is a gradual infusion of this layer.

Given that the CMAS melts at $\sim 1230^{\circ} \mathrm{C}$ [9], at $1250^{\circ} \mathrm{C}$ the molten CMAS can flow freely into the porous YSZ driven by gravity. Meanwhile, the fine pores/cracks also create a capillary pressure, which draws the molten CMAS into the pores. In order to compare the contribution from these two factors, two test coupons of the same size (1 $\mathrm{mm} \times 0.3 \mathrm{~mm} \times 3 \mathrm{~mm}$ matchstick) were prepared and sandwiched together with CMAS between them as illustrated in Figure 4 (a). From a CT scan of the stack prior to thermal exposure, the equivalent CMAS loading (assuming the loading was shared by the TBCs at top and bottom) was estimated to be $10.6 \pm 1.0 \mathrm{mg} / \mathrm{cm}^{2}$. The stack was exposed to $1250^{\circ} \mathrm{C}$ for $60 \mathrm{~min}$ and then rescanned by X-ray CT.

Figure 4 (b) and (c) compare the virtual cross-sections through the centre of the TBC stack. There is no appreciable difference in the infiltration depth between the top and bottom TBCs. This suggests that capillary pressure drives the CMAS infiltration process. Both TBCs have each developed a two-layer structure rather like that in Figure 2. In contrast to that case, there is no sign of infusion into the intact layers possibly due to a lower CMAS loading. 
In summary, non-destructive time-lapse X-ray $\mu$-CT has been used to follow the combined with DVC means that it can detect quite subtle movements of the CMAS and the associated strain changes over time. The evolution of the TBC microstructure by the CMAS infiltration is marked and has been elucidated. Based on these microstructure observations, the following conclusions can be reached:

- The CMAS quickly (certainly within 20 minutes at $1250^{\circ} \mathrm{C}$ ) infiltrates the CMAS loading driven by strong capillary driving forces along the inter-splat boundaries. This causes significant $(70 \%)$ expansion and exfoliation of the region immediately below the surface. The depth of this exfoliated region appears to be limited by the CMAS loading.

- Over a longer timescale there is some loss of CMAS from this exfoliated region causing it to deflate slightly. This is accompanied by a much lower level of swelling of the intact region beneath $(<15 \%)$.

- The onset of exfoliation at the coating surface is not dependent on the CMAS loading while the depth of the exfoliated region and the onset of the observable infusion into the intact layer are dependent on the CMAS loading;

Under real service conditions, the CMAS would be expected to accumulate over time. Given that infiltration is rapid this may cause progressive infiltration and exfoliation with increasing depth over time. Further in practice the temperature gradient though the TBC thickness may lead to different infiltration behaviour, limiting the penetration depth. These idealised experiments suggest that time-lapse X-ray and DVC could be combined in future with in-situ investigations of CMAS infiltration to examine the effect of realistic temperature gradients as well as the effect of constraint from the substrate. Nevertheless, these experiments provide valuable insights into CMAS infiltration and can underpin models of the process needed for better lifetime prediction. 


\section{Acknowledgements}

The authors are grateful for access to the Engineering and Physical Science Research Council (EPSRC) funded Henry Royce Institute (EP/P025021/1) for access to the Henry Moseley X-ray Imaging Facility equipment funded through grants (EP/F007906/1, EP/F001452/1,EP/I02249X, EP/M010619/1, EP/F028431/1, and EP/M022498/1). PJW acknowledges support from the European Research Council grant No. 695638 CORREL-CT for the funding of the laser microPREP. 


\section{References}

1. Evans, A.G., et al., Mechanisms controlling the durability of thermal barrier coatings. Progress in Materials Science, 2001. 46(5): p. 505-553.

2. Padture, N.P., M. Gell, and E.H. Jordan, Materials science - Thermal barrier coatings for gasturbine engine applications. Science, 2002. 296(5566): p. 280-284.

3. Clarke, D.R. and C.G. Levi, Materials design for the next generation thermal barrier coatings. Annual Review of Materials Research, 2003. 33: p. 383-417.

4. Clarke, D.R., M. Oechsner, and N.P. Padture, Thermal-barrier coatings for more efficient gasturbine engines. Mrs Bulletin, 2012. 37(10): p. 891-902.

5. Chen, Y., et al., Characterization and understanding of residual stresses in a NiCoCrA/Y bond coat for thermal barrier coating application. Acta Materialia, 2015. 94: p. 1-14.

6. Krause, A.R., et al., Calcia-magnesia-alumino-silicate (CMAS)-induced degradation and failure of air plasma sprayed yttria-stabilized zirconia thermal barrier coatings. Acta Materialia, 2016. 105: p. 355-366.

7. Darolia, R., Thermal barrier coatings technology: critical review, progress update, remaining challenges and prospects. International Materials Reviews, 2013. 58(6): p. 315-348.

8. Levi, C.G., et al., Environmental degradation of thermal-barrier coatings by molten deposits. Mrs Bulletin, 2012. 37(10): p. 932-941.

9. Shan, X., et al., Buckling failure in air-plasma sprayed thermal barrier coatings induced by molten silicate attack. Scripta Materialia, 2016. 113: p. 71-74.

10. Garces, H.F., B.S. Senturk, and N.P. Padture, In situ Raman spectroscopy studies of hightemperature degradation of thermal barrier coatings by molten silicate deposits. Scripta Materialia, 2014. 76: p. 29-32.

11. Drexler, J.M., et al., Air-plasma-sprayed thermal barrier coatings that are resistant to hightemperature attack by glassy deposits. Acta Materialia, 2010. 58(20): p. 6835-6844.

12. Krause, A.R., X. Li, and N.P. Padture, Interaction between ceramic powder and molten calciamagnesia-alumino-silicate (CMAS) glass, and its implication on CMAS-resistant thermal barrier coatings. Scripta Materialia, 2016. 112: p. 118-122.

13. Kramer, S., et al., Thermochemical interaction of thermal barrier coatings with molten CaOMgO-Al2O3-SiO2 (CMAS) deposits. Journal of the American Ceramic Society, 2006. 89(10): p. 3167-3175.

14. Krause, A.R., et al., 2ZrO(2)center dot Y2O3 Thermal Barrier Coatings Resistant to Degradation by Molten CMAS: Part I, Optical Basicity Considerations and Processing. Journal of the American Ceramic Society, 2014. 97(12): p. 3943-3949.

15. Hannink, R.H.J., P.M. Kelly, and B.C. Muddle, Transformation toughening in zirconiacontaining ceramics. Journal of the American Ceramic Society, 2000. 83(3): p. 461-487.

16. Levi, C.G., Science Underpinning TBC Design to Overcome the CMAS Threat to Progress in Gas Turbine Technology. 2015, The Regents of the University of California, Santa Barbara Campus

17. Jackson, R.W., et al., Interaction of molten silicates with thermal barrier coatings under temperature gradients (vol 89, pg 396, 2015). Acta Materialia, 2015. 94: p. 328-328.

18. Zhao, Y., et al., Investigation of interfacial properties of atmospheric plasma sprayed thermal barrier coatings with four-point bending and computed tomography technique. Surface \& Coatings Technology, 2012. 206(23): p. 4922-4929.

19. Zhang, X., et al., Microstructural degradation of Electron Beam-Physical Vapour Deposition Thermal Barrier Coating during thermal cycling tracked by $X$-ray micro-computed tomography. Scripta Materialia, 2018. 152: p. 79-83.

20. Khoshkhou, D., et al., Three-dimensional displacement mapping of diffused Pt thermal barrier coatings via synchrotron $X$-ray computed tomography and digital volume correlation. Scripta Materialia, 2016. 115: p. 100-103. 
21. Zhang, X., et al., 3D characterization of porosity in an air plasma-sprayed thermal barrier coating and its effect on thermal conductivity. Journal of the American Ceramic Society, 2018. 101(6): p. 2482-2492.

22. Ahmadian, S., A. Browning, and E.H. Jordan, Three-dimensional X-ray micro-computed tomography of cracks in a furnace cycled air plasma sprayed thermal barrier coating. Scripta Materialia, 2015. 97: p. 13-16.

23. Zhu, W., et al., The evolution of pores in thermal barrier coatings under volcanic ash corrosion using X-ray computed tomography. Surface and Coatings Technology, 2019. 357: p. 372-378.

24. Zhang, X., et al., Determination of local residual stress in an air plasma spray thermal barrier coating (APS-TBC) by microscale ring coring using a picosecond laser. Scripta Materialia, 2019. 167: p. 126-130.

25. Burnett, T.L. and P.J. Withers, Completing the picture through correlative characterization. Nature Materials, 2019.

26. Lai, W.M., D. Rubin, and E. Krempl, CHAPTER 3 - Kinematics of a Continuum, in Introduction to Continuum Mechanics (Fourth Edition), W.M. Lai, D. Rubin, and E. Krempl, Editors. 2010, Butterworth-Heinemann: Boston. p. 69-153.

27. Bansal, N.P. and S.R. Choi, Properties of CMAS glass from desert sand. Ceramics International, 2015. 41(3): p. 3901-3909. 


\section{Figure captions}

Figure 1 Comparison of the same region of interest for the as-received APS TBC after CMAS deposition (a) a virtual X-ray $\mu-C T$ slice and (b) the corresponding polished section viewed by SEM (BSE mode). The inter-splat pores (yellow arrow), fragmented YSZ zones (yellow square) and inter-splat cracks (red ellipse) are visible under X-ray $\mu$-CT and SEM.

Figure 2 Cross-sectional virtual slice through the centre of the tested coupon showing the same region of interest at different stages of CMAS infiltration: (a) asdeposited and after exposure at $1200{ }^{\circ} \mathrm{C}$ for (b) $20 \mathrm{~min}$; (c) $40 \mathrm{~min}$ and (d) $60 \mathrm{~min}$. Videos showing the CMAS infiltration process are included in Appendix B.

Figure 3 Volume expansion profiles through the thickness of the TBC after different heat treatment time. The error bar for the volume strain in the intact layer represents the standard deviation from the DVC results.

Figure 4 Sandwich sample arrangement for infiltration test: (a) schematic showing the sample geometry and X-ray $\mu$-CT virtual cross-sections of the same region of interest (b) before infiltration and (c) after thermal exposure to $1250^{\circ} \mathrm{C}$ for $60 \mathrm{mins}$. The yellow dash line highlights the interface between the exfoliated layer and the intact layer. 


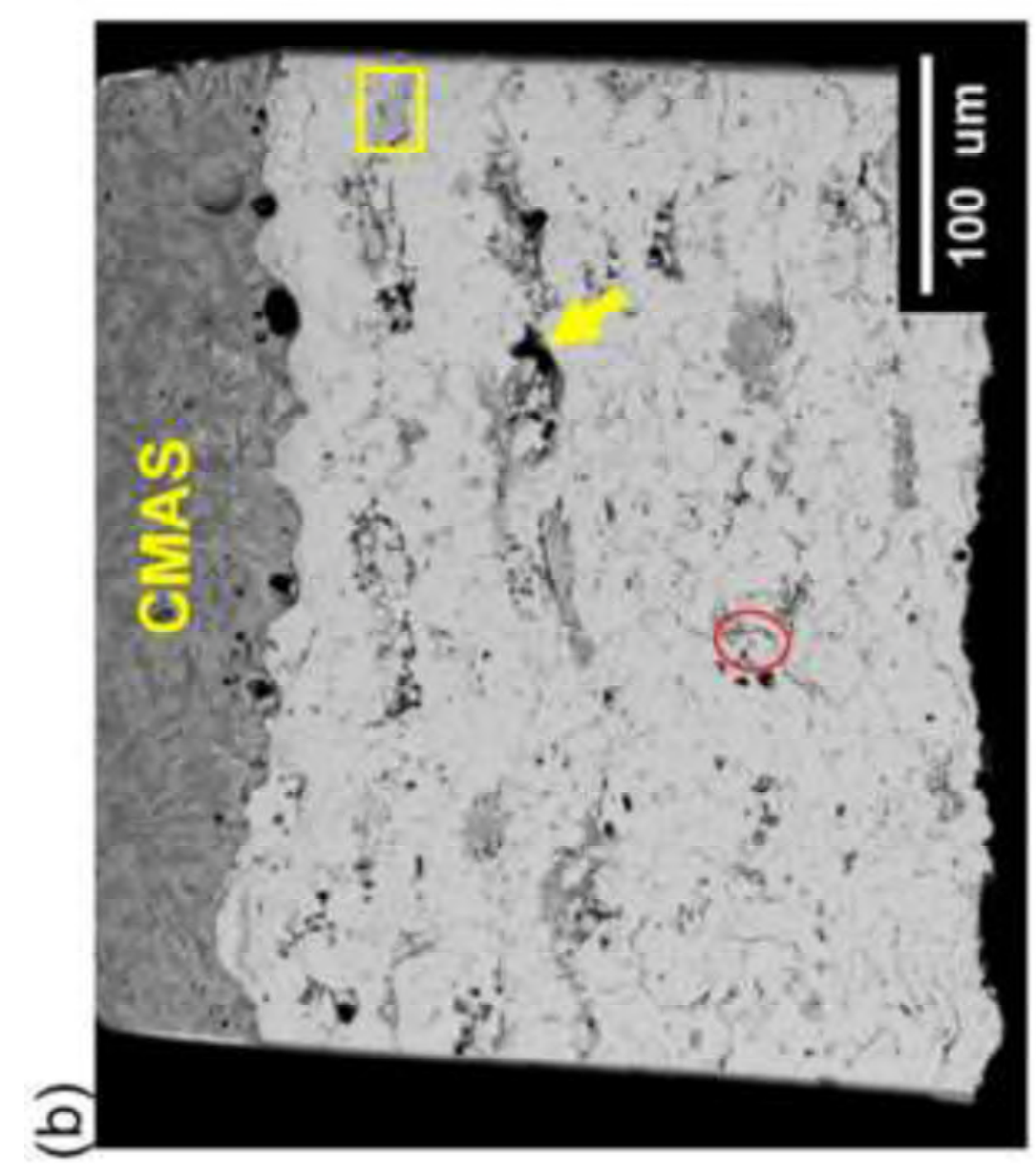

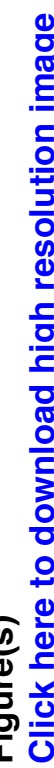

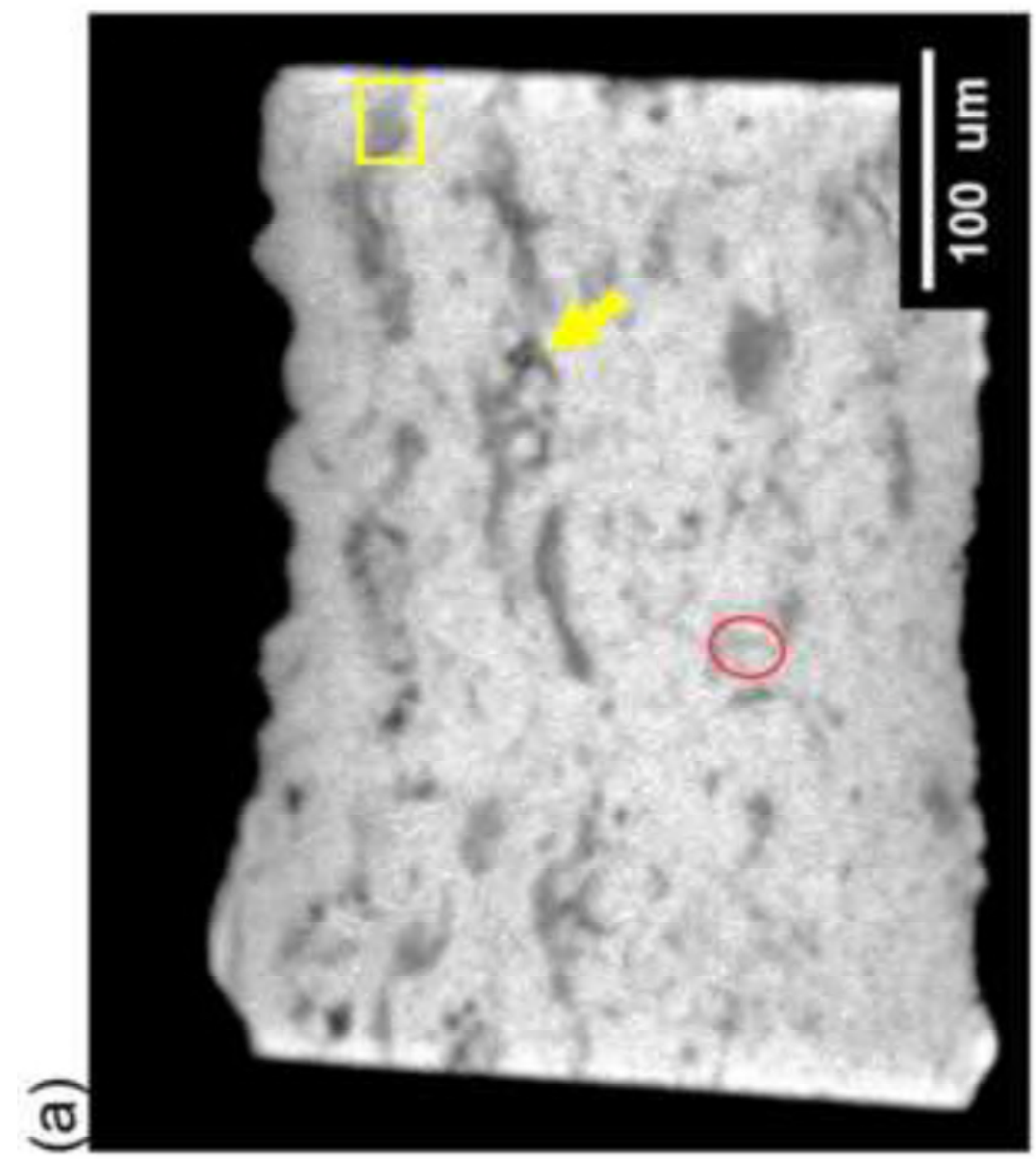



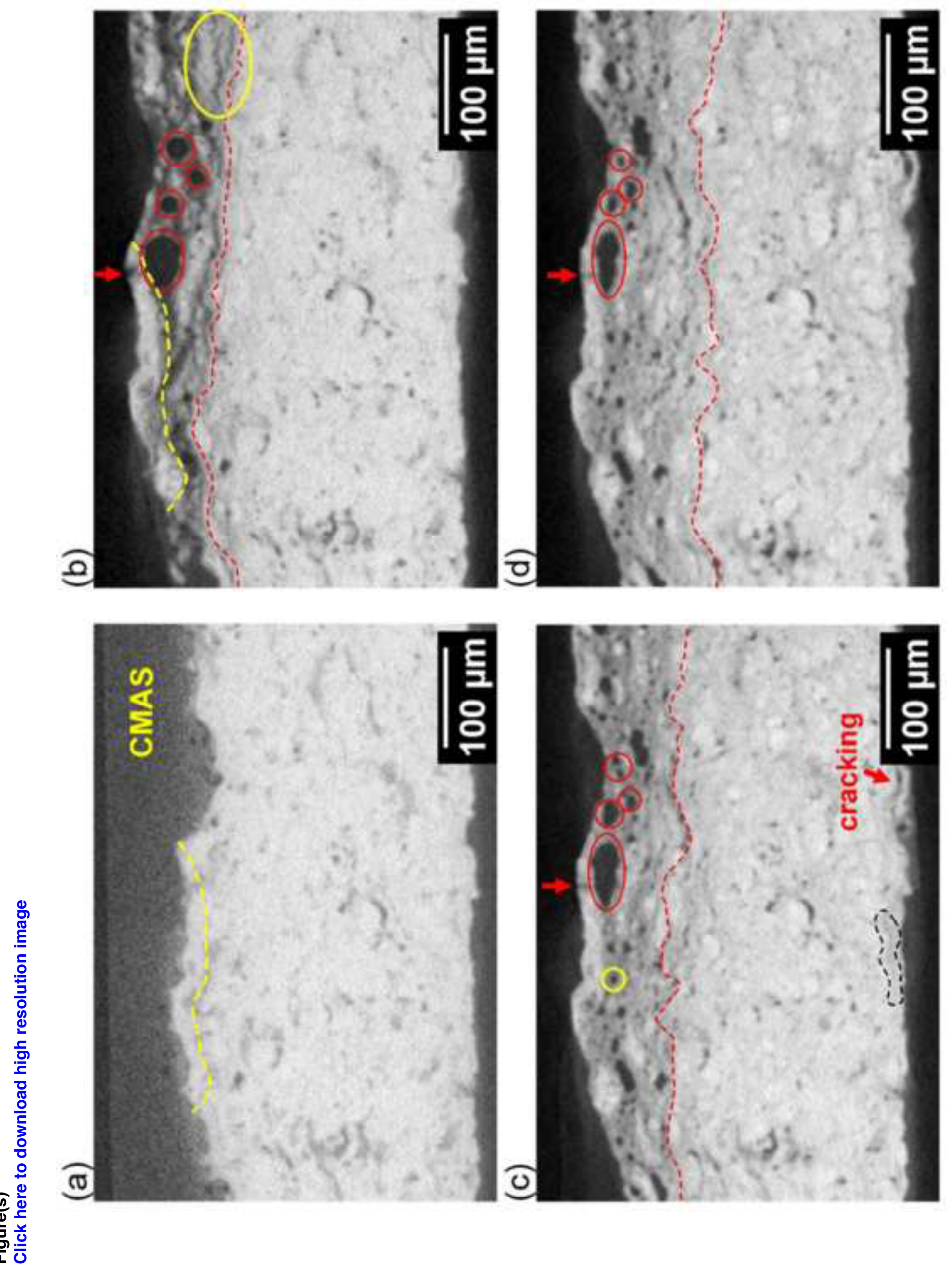


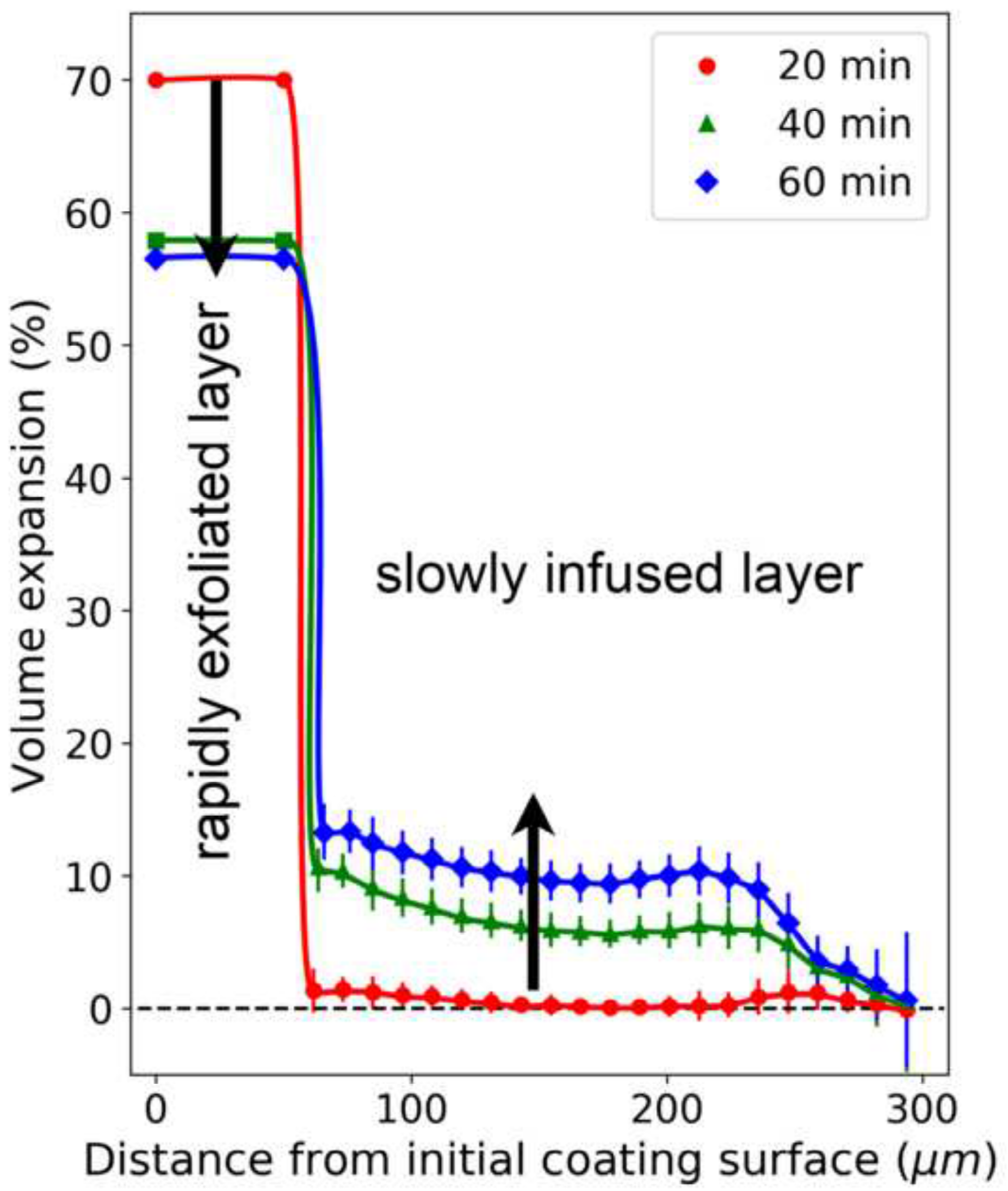




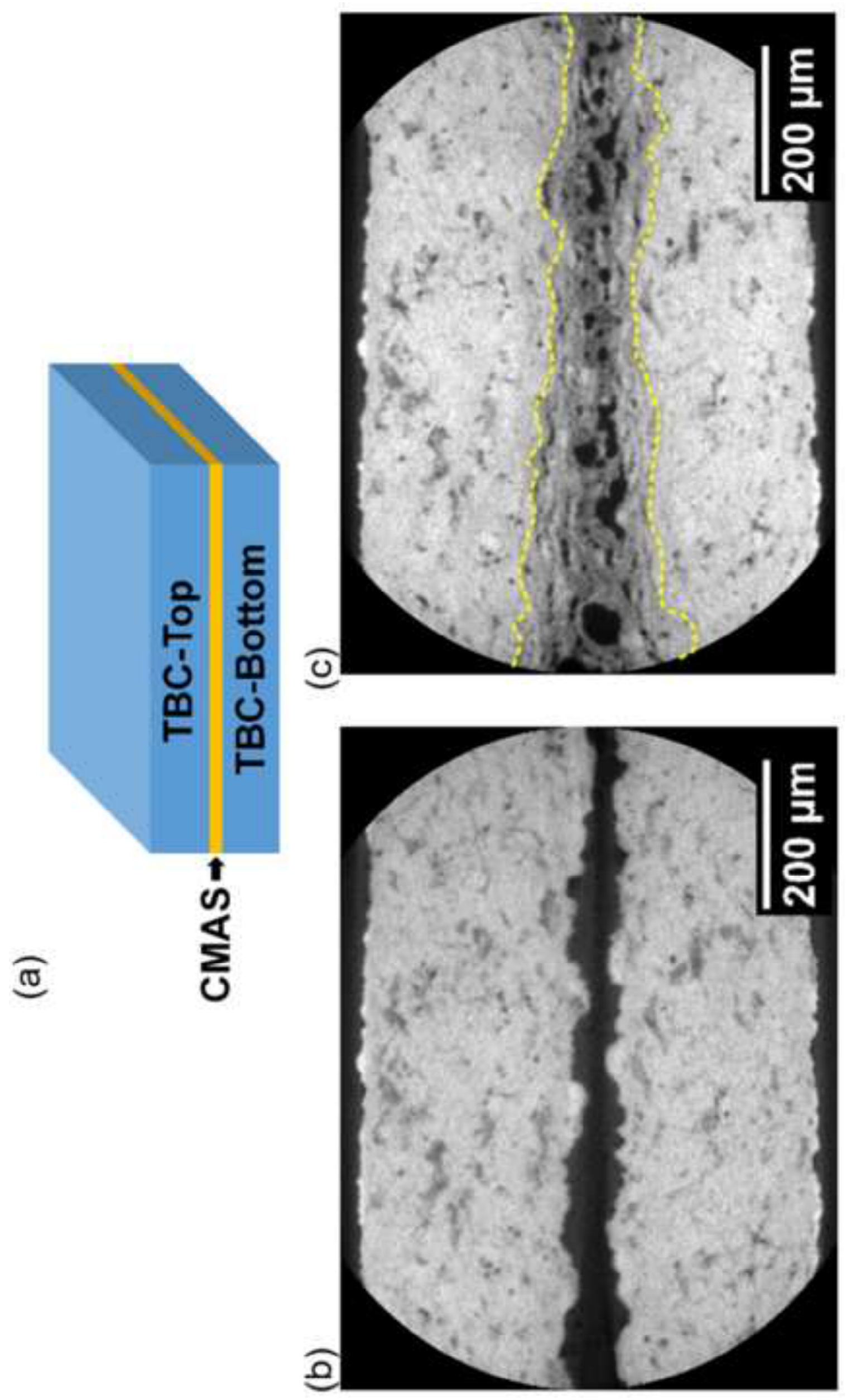




\section{Appendix A}

Quantitative image analysis was conducted to estimate the local CMAS loading for each specimen. This was achieved by segmenting the cross-sectional micrographs obtained by X-ray $\mu$-CT as shown in Figure A1(a) and (b). The volume of the CMAS is estimated by counting the number of voxels corresponding to the CMAS phase and the mass of the CMAS is estimated by multiplying its volume with its density $\left(\sim 2.69 \mathrm{~g} / \mathrm{mm}^{3}[27]\right)$.

(a)

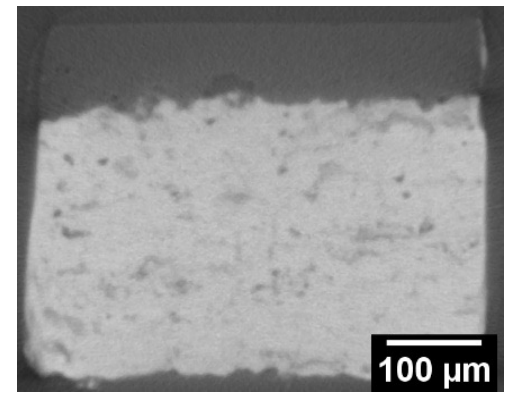

(b)

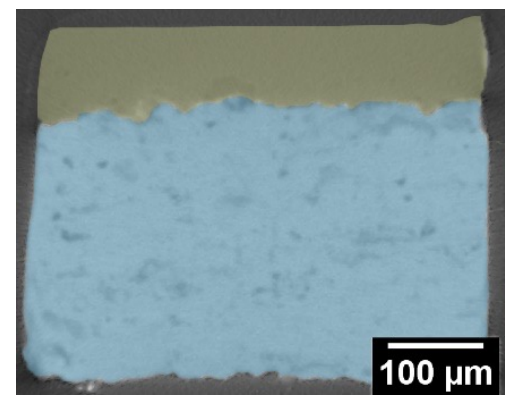

(c)

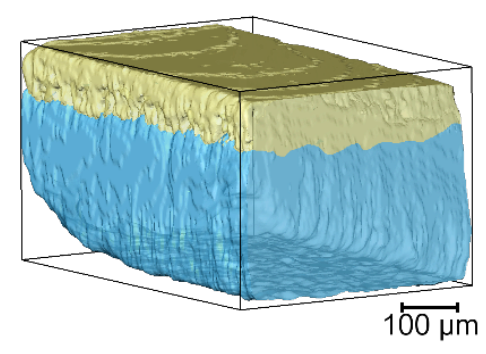

Figure A1 X-ray $\mu$-CT micrographs for estimation the local CMAS loading: (a) raw virtual slice; (b) segmented image with the CMAS and YSZ coating coloured differently and (c) 3D volume rending showing the CMAS on top of the YSZ coating. 
Appendix B

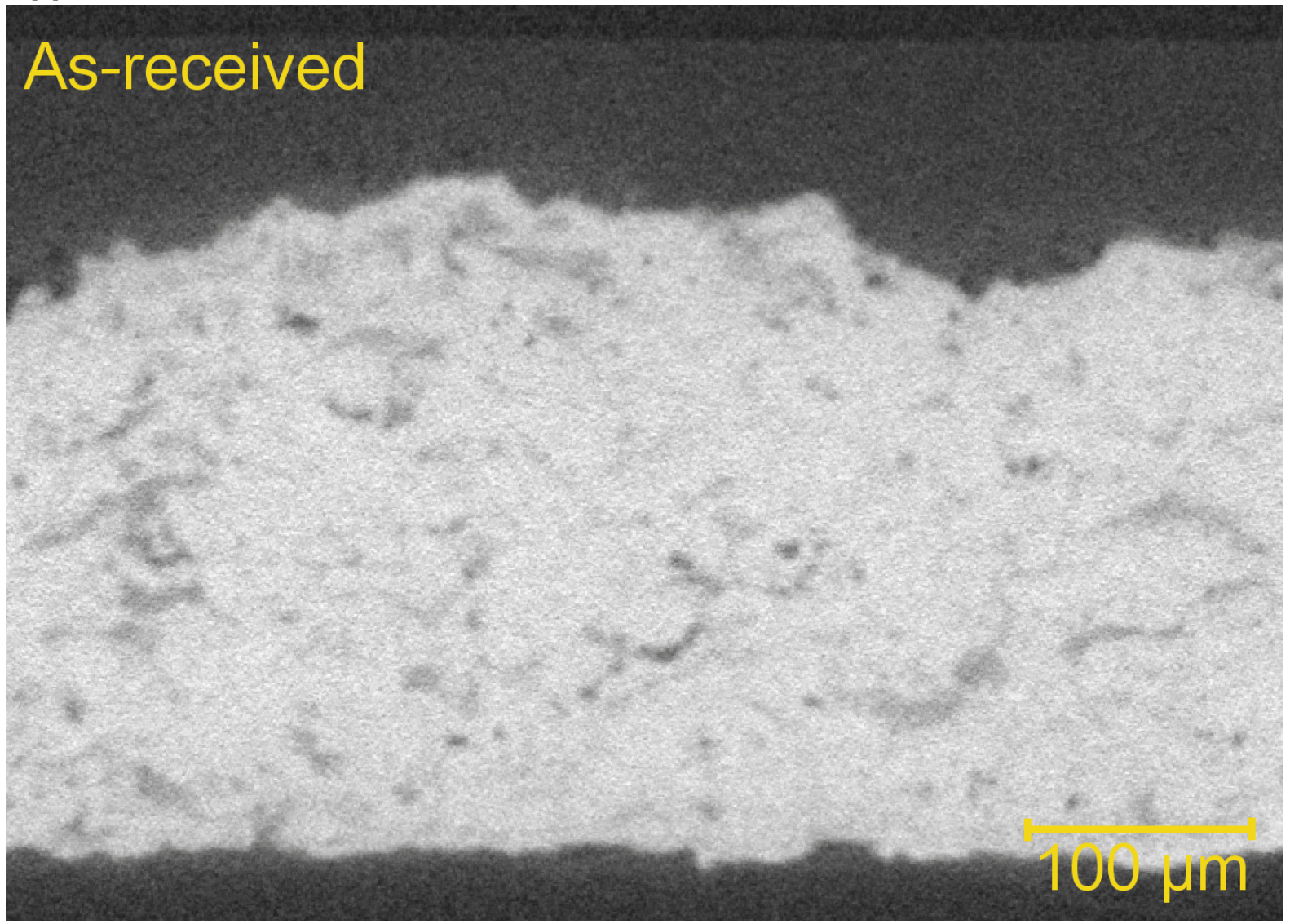

Video B1. Video showing the same virtual cross section through the middle of the test coupon at different stages of CMAS infiltration. 


\section{Appendix C}

The average volume expansion for the intact layer has been calculated according to Eq. 1 using the displacement field determined by DVC. The displacement fields determined by DVS are shown in Fig. C1. The top exfoliated layer has deformed too much for correlation to be achieved. The first 20 min has induced little swelling in the intact layer. The outward-pointing arrows as seen in the virtual cross sections for 40 min and 60 min suggest a volume expansion induced by the CMAS.

(a)
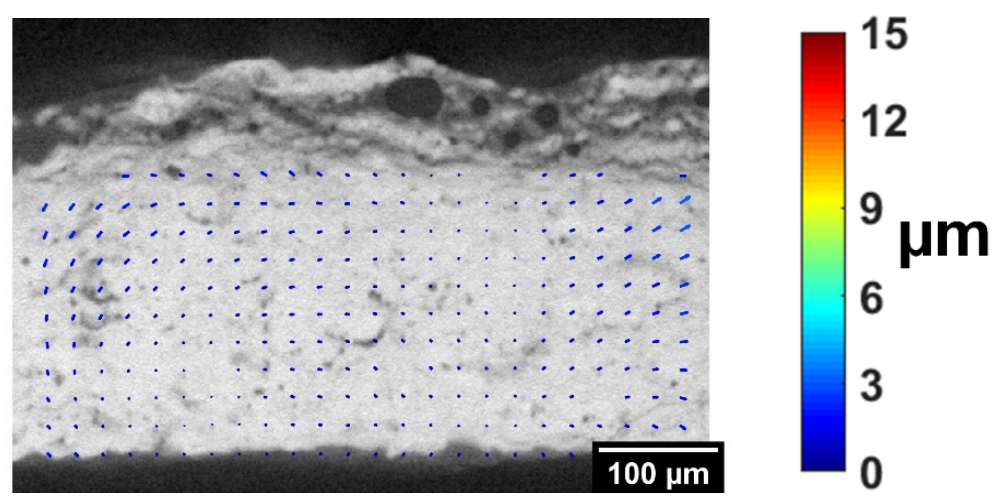

(b)

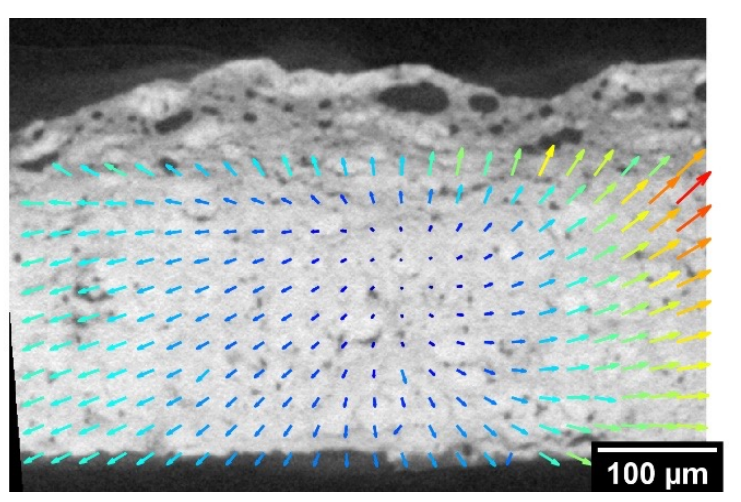

(c)

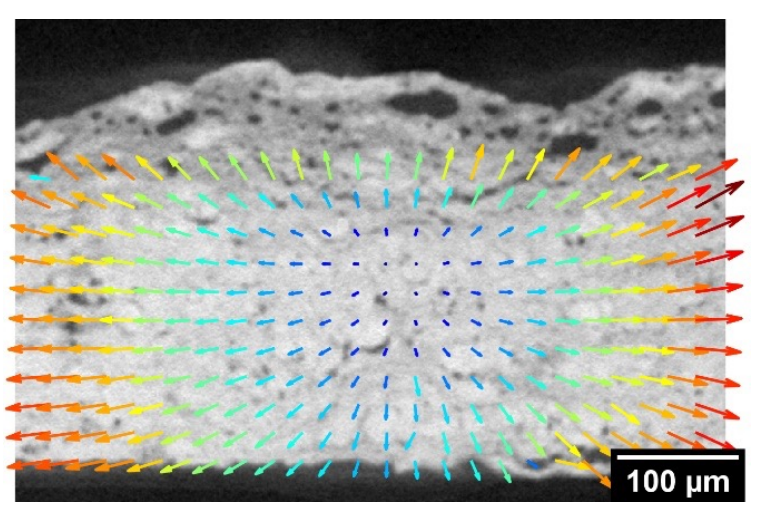

Figure C1 Displacement fields below the severely infiltrated zone induced by CMAS infiltration after heat treatment at $1200{ }^{\circ} \mathrm{C}$ for (a) $20 \mathrm{~min}$; (b) $40 \mathrm{~min}$ and (c) $60 \mathrm{~min}$. The arrows coloured using the magnitude of the displacement vector. 